\title{
O Brasil e o mundo no limiar do novo século: diplomacia e desenvolvimento
}

\author{
LUIZ FELIPE DE SEIXAS CORRÊA*
}

\begin{abstract}
“... whatever its faults or problems, no outsider today sees Brazil as a joke. The biggest country in its region is now treated - and acts - as such a country deserves to be and, in the long term, has to be" (The Economist, "Brazil's steady nerve”, 10/10/98, p.15).
\end{abstract}

Durante o primeiro mandato do Presidente Fernando Henrique Cardoso (1995-98), o exercício da diplomacia foi fortemente beneficiado pela retomada de um sentimento de auto-estima da sociedade nacional e pela repercussão externa positiva dos avanços políticos, econômicos e sociais do país. O Itamaraty pôde trabalhar com renovada desenvoltura, sem as inibições que tanto o haviam limitado no passado ainda recente, derivadas do regime autoritário entre 1964-85, das incertezas da transição política subseqüente e das dificuldades econômicas do período 1981-92.

A confiança do Brasil em suas próprias capacidades e o respeito da comunidade internacional asseguraram o êxito de uma série de operações diplomáticas de grande envergadura. Continuamos a consolidar e aprofundar o MERCOSUL. Assinamos em 1996 acordos de integração econômica com o Chile e a Bolívia. Tivemos papel de liderança nas discussões sobre o lançamento de negociações para a futura conformação da Área de Livre Comércio das Américas (ALCA), e logramos imprimir a esse processo um ritmo compatível com os interesses nacionais. Estivemos à frente dos entendimentos que levaram à convocação da primeira reunião de cúpula entre Chefes de Estado e de Governo da América Latina-Caribe e da União Européia, que se realizará no Rio de Janeiro nos dias 28 e 29 de junho próximos. Na América do Sul, o Brasil trabalhou com êxito pela manutenção do ambiente de paz, estabilidade e entendimento que a distingue de modo tão favorável na comparação com outros continentes. Juntamente 
com os parceiros do MERCOSUL, atuamos em favor da consolidação do regime democrático no Paraguai. O Presidente Fernando Henrique Cardoso liderou pessoalmente os entendimentos que levaram à celebração de acordo de paz entre o Equador e o Peru, em outubro de 1998, em cerimônia realizada em Brasília. No plano multilateral, o Brasil - utilizando uma expressão do Ministro das Relações Exteriores, Luiz Felipe Lampreia - "resgatou hipotecas” que ainda pesavam sobre nossa presença no mundo. A ratificação em 1998 do Tratado de Não-Proliferação de Armas Nucleares (TNP) foi a iniciativa de maior relevância e visibilidade nesse sentido.

Essa linha de avaliação positiva sobre o trabalho da diplomacia brasileira no governo Fernando Henrique Cardoso tem sido repetida por importantes órgãos da imprensa nacional e internacional. ${ }^{1}$

Na virada de ano 1998-99, que coincidiu com a reeleição do Presidente Fernando Henrique Cardoso para um segundo mandato (1999-2002), criou-se, porém, uma nova situação. A crise de liquidez nos mercados financeiros internacionais atingiu duramente o Brasil e trouxe conseqüências importantes para a operação da diplomacia do país. O presente texto examina as prioridades da política externa brasileira neste novo momento, e em que medida as condições externas e internas supervenientes condicionam ou limitam o exercício da diplomacia. Na primeira parte, o texto faz comentários de natureza geral e histórica sobre as visões dos brasileiros e do mundo exterior a respeito do Brasil. A segunda parte contém observações gerais a respeito do atual cenário internacional e sobre suas características que não operam em favor do desenvolvimento de países como o Brasil. A terceira parte, por fim, trata da agenda diplomática do país em 1999.

\section{O Brasil e a busca do desenvolvimento}

O Brasil busca arduamente adaptar-se aos novos tempos e às novas condições da ordem internacional. Muitas vezes, não obstante, somos criticados pelo que se pode perceber como uma certa lentidão do sistema político-institucional brasileiro em promover as mudanças necessárias.

Nem sempre é fácil compreender o que está acontecendo no país. As diferentes dimensões em que se desdobram as realidades contrastantes do Brasil, suas ambivalências e seus ritmos às vezes indecifráveis constituem um duro teste para a imaginação dos que tentam explicá-lo. Da mesma forma que a sua formação histórica singular desafia a capacidade dos que se dedicam às ciências do passado para compreender o presente do Brasil e pensar sobre seu futuro.

Os tempos brasileiros são, efetivamente, muito particulares. Mas têm sua razão de ser, sua explicação e, sobretudo, suas virtudes. Ao aproximar-se o novo milênio, que gerações de brasileiros anteviam como o umbral de desenvolvimento econômico e social do país, o Brasil continua a enfrentar uma série de desafios. O 
sonho ainda não se realizou. O Brasil segue sendo, nas palavras do presidente Fernando Henrique Cardoso, um país injusto, que quotidianamente sofre as conseqüências da má distribuição da riqueza e que, como o demonstram fatos e situações recentes, se vê forçado a lidar com temas primários tais como a distribuição da terra, a destruição do meio ambiente, a violência estrutural, as más condições sanitárias e a baixa qualidade da educação. Mas, ao mesmo tempo, é um país que produz bens e serviços de alta tecnologia, que dispõe de meios intelectuais, empresariais e governamentais plenamente integrados com o que há de mais avançado no mundo. Um país, portanto, que se apresenta frente a si próprio e frente ao mundo em fragmentos contraditórios e imagens freqüentemente desconexas. Um país que é como um quebra-cabeça, em busca de uma visão integral capaz de revelar o sentido profundo de suas diferentes realidades.

Essa preocupação não é nova. Acompanha a história do Brasil desde suas origens, especialmente a partir do início do século XX, quando se tornou evidente a incapacidade dos dirigentes brasileiros de atender às expectativas de progresso e modernização despertadas pela proclamação da República em 1889. São conhecidos os paradigmas cristalizados naquele momento: de um lado, o ufanismo, surgido em meio à euforia nacionalista que caracterizou as comemorações do IV Centenário do Descobrimento do Brasil, representado pelo Conde Afonso Celso, autor do célebre opúsculo Por que me ufano do meu país; de outro, o pessimismo e o desprezo pelo nacional, tão dramaticamente expressados por Paulo Prado em seu Retrato do Brasil.

As ciências sociais no Brasil ao longo de todo o século XX estiveram sempre fixadas na discussão de temas como a formação nacional, as raízes de nosso subdesenvolvimento e, ao mesmo tempo, em propostas ou visões para superar o atraso. ${ }^{2}$ São exemplos dessa constatação as obras clássicas de Gilberto Freyre (Casa-Grande e Senzala), Sérgio Buarque de Holanda (Raízes do Brasil), Oliveira Viana (Populações Meridionais do Brasil) ou Vianna Moog (Bandeirantes e Pioneiros). No início dos anos noventa, apenas para citar um exemplo mais atual, Francisco Weffort deu seguimento a essa tradição com o belo ensaio A América Errada.

Entre os extremos da exaltação nacionalista de Afonso Celso e a autoflagelação europeizante de Paulo Prado, custou muito ao pensamento brasileiro encontrar o equilíbrio de hoje. Depois de um longo caminho que conduziu o país por constantes espasmos de demagogia e autoritarismo, chegamos ao V Centenário do Descobrimento e nos preparamos para cruzar a marca mítica do milênio com um sentido comum e uma circunspecção inéditos. Não mais estamos à beira do abismo perene que, desde os tempos de Dom João VI, ameaça tragar a sociedade brasileira, e tampouco nos encontramos no paraíso terrestre que, embalado pelas descrições edênicas da carta do escrivão Caminha a Dom Manuel, o Venturoso, em 1500, o brasileiro se obstinava em encontrar, contra todas as evidências, nas 
asperezas da sua realidade quotidiana. A sociedade brasileira parece haver finalmente despertado de suas fantasias, positivas ou negativas. As reações de equilíbrio da população no período de turbulências cambiais entre janeiro e março de 1999 foram indicativas desse novo estado de espírito. Em nenhum momento perdeu-se a crença quanto à possibilidade de manter o país no rumo da estabilização econômica. Ao contrário: as reações espontâneas da própria sociedade (consumidores e agentes econômicos) foram determinantes para evitar a volta da inflação, fato que levou o Presidente Fernando Henrique Cardoso a dizer que a "âncora” do Plano Real é o povo brasileiro.

Como se, ao final de um longo processo analítico, os brasileiros finalmente tivéssemos assumido nossa própria personalidade e nossa própria realidade, com seus notáveis êxitos e com toda a carga de seus desacertos. Um país em sua dimensão de sociedade nacional é, essencialmente, um conjunto de pessoas associadas em torno de ideais e comportamentos comuns. O estado de espírito de um país é tão importante quanto o estado das coisas. Assim como as pessoas no plano individual, as coletividades nacionais se movem no espaço interior de um país e se relacionam com o mundo exterior em função de anseios, frustrações, complexos, temores e ambições. Em função, enfim, de toda a gama de fatores que condicionam o processo decisório individual e coletivo, como por exemplo o grau de ajuste e sociabilidade de cada um. Todo pensamento legítimo, na expressão de Manuel Bomfim, antes de ser pensado foi sentimento. Bomfim, um dos intelectuais antimonárquicos mais importantes, participante ativo da demolição institucional da monarquia brasileira e da construção da utopia republicana de princípios do século, imaginava um brasileiro dono de seu pensamento, desprovido de ceticismos e desinteresses, um homem que "transforma em conceito o que sente, rompendo com as fórmulas correntes para afirmar a indispensável renovação”; ou, como queria Euclides da Cunha, autor de Os Sertões, um livro certamente ainda atual para a compreensão das diferentes dimensões brasileiras, um brasileiro capaz de deixar de lado seu sentimentalismo rudimentar, "a exploração pecaminosa de todas as dores e todas as calamidades”, e de bater-se à luz de seus princípios, "ainda que adversos, sem o acompanhamento obrigatório dessas eternas loas ao infortúnio, dessa constante ladainha de agruras”.

O brasileiro imaginado no início do século pela visão de Bomfim e de Euclides parece ter tomado forma agora que chegamos ao seu final, em meio a tantas inquietações e dúvidas persistentes. Frente a um espelho imaginário, o Brasil se vê hoje em sua totalidade. Um país diante de suas próprias circunstâncias: nem o mais atrasado, nem o mais adiantado; nem o mais rico, nem o mais pobre; nem o mais justo, nem tampouco o mais injusto. Um país que busca transformar-se não por impulsos autoritários ou visões impostas, mas sim mediante a gestação de consensos aproximativos que, mesmo não sendo o caminho mais rápido, constituem certamente o mais seguro e duradouro. 
O Brasil tem pela frente uma agenda organizada sob a forma de grandes antinomias que se expressam, por exemplo, em tendências oscilantes entre abertura e fechamento; entre integração e alienação; crescimento e estagnação; harmonização e imposição; participação social e confrontação social; modernização e atraso. Ainda que subsistam no país segmentos que, consciente ou inconscientemente, favorecem políticas tendentes a acentuar o lado negativo dessas antinomias, felizmente o que hoje prevalece na sociedade brasileira é uma visão positiva, uma deliberação afirmativa pela abertura, pela integração, pelo crescimento, pela harmonização, pela participação social e pela modernização.

O ano eleitoral de 1998 foi, sob todos os aspectos, crucial para o prosseguimento do processo de transformações internas e adaptações externas do Brasil. À luz de sua nova maturidade, a sociedade brasileira tomou decisões fundamentais sobre o futuro do país e sua inserção no mundo. As eleições presidenciais coincidiram com um momento de grave deterioração da crise financeira internacional iniciada em meados de 1997 na região da Ásia-Pacífico. A moratória russa de agosto de 1998 agravara ainda mais as dificuldades que países emergentes como o Brasil já vinham enfrentando para manter o acesso a créditos e financiamentos externos. O Presidente Fernando Henrique Cardoso, em plena campanha eleitoral, anunciou que seria necessário um esforço renovado de austeridade fiscal, para que se pudesse manter a estabilidade econômica conquistada com o Plano Real. A sociedade brasileira assimilou esse gesto de grandeza política e de sinceridade pessoal e renovou o mandato do Presidente, confiante em sua direção para que o país continuasse no rumo da estabilização, das reformas e da abertura.

O Brasil foi durantemente golpeado pela instabilidade dos mercados financeiros internacionais. O governo Fernando Henrique Cardoso havia-se decidido, desde 1995, por um ritmo de gradualismo na implementação de reformas econômicas. Buscara-se sempre o mais amplo grau possível de consenso entre os partidos políticos e os diversos grupos sociais. Partia-se da constatação de que os mercados financeiros internacionais estavam cientes dos avanços que o país vinha realizando e manteriam sua confiança e disposição de financiar os déficits em transações correntes.

A partir da moratória russa, contudo, o quadro externo alterou-se de modo dramático. Em um contexto momentâneo de grave crise nos mercados financeiros - por muitos caracterizada como a mais grave desde o início do funcionamento das instituições de Bretton Woods após a II Guerra Mundial -, os capitais internacionais afastaram-se dos países emergentes de uma forma geral, sem fazer distinções em favor daqueles que, como o Brasil, tinham (e têm) a mais absoluta estabilidade política, compromisso com as reformas econômicas e o saneamento fiscal, sistema bancário sólido, ausência de "bolhas especulativas" e empresas pouco endividadas. 
O Brasil viu-se na contingência de ter de recorrer ao Fundo Monetário Internacional (FMI). Em novembro, o país assinou uma primeira carta de intenções com o Fundo, e recebeu compromissos de ajuda externa de vários organismos financeiros internacionais e de governos de países industrializados no valor de US\$ 41, 5 bilhões. O apoio político do governo dos Estados Unidos foi decisivo para esse resultado.

Naquele momento, pareciam encaminhadas as medidas que possibilitariam ao Brasil a travessia do credit crunch nos mercados financeiros internacionais. Na seqüência, contudo, obstáculos no Congresso Nacional, em dezembro, para aprovação de medidas de ajuste fiscal (em especial o atraso na votação da CPMF e a derrota do Governo no tema da contribuição previdenciária de servidores públicos) e as dificuldades no relacionamento entre a União e governadores empossados a 1\%1/99 transmitiram aos mercados a impressão de que o país como um todo ainda não se havia conscientizado da necessidade inadiável de corrigir o déficit fiscal - superior a 8\% do PIB em 1998.

Agravou-se a crise de confiança externa. A situação do balanço de pagamentos deteriorou-se rapidamente. Em meados de janeiro, o Governo foi levado a alterar sua política cambial. De uma política de desvalorizações graduais e controladas, passou-se à livre flutuação. Após momentos iniciais de dificuldades para adaptação ao novo cenário econômico, a determinação do Governo em manter o curso de saneamento fiscal e de reformas e abertura econômica conduziu o país em março/abril a um novo ponto de equilíbrio.

Uma série de fatores contribuiu para essa evolução positiva. Ainda em fevereiro, o Congresso Nacional aprovou, por fim, as propostas governamentais sobre contribuições previdenciárias de servidores públicos, inclusive os inativos. Em encontro conjunto com 26 dos 27 governadores estaduais, o Presidente Fernando Henrique deu início a uma distensão no diálogo entre a União e os Estados. Em março, foi assinada uma nova carta de intenções com o FMI. O Governo Federal tornou explícita a decisão de substituir a política cambial por uma meta inflacionária (ao lado das medidas de ajuste fiscal) como âncora para a estabilização econômica. Já em meados do mesmo mês, os diferentes índices de inflação que haviam apresentado fortes altas logo após o impacto inicial da desvalorização do Real voltaram a apresentar tendência declinante. A balança comercial será superavitária em 1999, e haverá um decréscimo substancial no déficit da balança de transações correntes. No final de abril, o Governo realizou com grande êxito emissão de títulos no mercado internacional. O Brasil continua a receber importantes fluxos de investimentos diretos (possivelmente em nível suficiente para financiar todo o déficit da balança de transações correntes em 1999), os quais são talvez a mais importante demonstração de confiança - real e não apenas retórica - nas perspectivas de longo prazo de um país. 
Pode-se, portanto, dizer que o Brasil está no bom caminho para superar os momentos mais difíceis da crise econômica que o atingiu tão duramente. É fundamental ter sempre presente, por outro lado, que a análise de um diplomata sobre as potencialidades de um país e sua capacidade de projeção externa não se deve fixar em momentos específicos, por mais positivos ou negativos que possam ser. Por exigência de sua profissão, o diplomata deve manter a visão do longo prazo, das tendências mais permanentes.

Independentemente das flutuações de curto prazo nas percepções internas e externas a respeito do Brasil, há toda uma série de considerações que estão sempre presentes no planejamento e na execução da política externa nacional:

$1^{\circ}$ ) entre os países emergentes, o Brasil destaca-se pela solidez de seu regime democrático e pela existência de um regime jurídico estável e transparente. O grau de liberdade sindical ou de imprensa em nada fica a dever na comparação com os países mais adiantados do mundo;

$2^{\circ}$ ) a efetiva dimensão econômica do País não se mede pela flutuação diária dos mercados financeiros e de câmbio. A desvalorização do Real não significa, naturalmente, que a economia brasileira tenha encolhido de um momento para outro. Os indicadores de produção física são os que contam. Medido pelo critério da paridade do poder de compra da moeda nacional (em oposição à utilização de taxas nominais que variam diariamente), o PIB brasileiro continua a ter um valor na faixa de US\$ 1 trilhão;

$3^{\circ}$ ) o elevado valor do estoque de investimentos estrangeiros diretos (IED) no Brasil representa sinal inequívoco de alto grau de confiança nas potencialidades de longo prazo do país. De acordo com dados da UNCTAD, o Brasil é o segundo mais importante receptor de IED entre os países emergentes, superado apenas pela China. O Brasil detém o quinto mais importante estoque de IED norteamericano em todo o mundo (cerca de US\$ 34,5 bilhões), superado apenas por Reino Unido, Canadá, Holanda e Alemanha. ${ }^{3}$ Conforme dados do Bundesbank, somos o mais importante destino de IED da Alemanha entre os países em desenvolvimento (estoque de US\$13,5 bilhões), seguido pelas Ilhas Cayman, pelo México e pela Argentina. Mesmo em meio às turbulências da mudança do regime cambial, manteve-se vivo o interesse dos investidores externos pelo Brasil. As últimas estimativas indicam que o ingresso líquido de recursos nessa rubrica no ano de 1999 será da ordem de US\$ 20 bilhões. No primeiro trimestre de 1999, o total líquido de IED recebido foi de US\$ 7,7 bilhões - valor superior em cerca de $50 \%$ ao déficit da balança de transações correntes, que foi de US\$ 5,17 bilhões; ${ }^{4}$

$4^{\circ}$ ) apesar de todas as injustiças sociais que continuam a caracterizar o Brasil, e que representam o mais sério obstáculo ao processo de desenvolvimento nacional, o país tem feito avanços consistentes - ainda que em ritmo insuficiente para resgatar sua “dívida” nessa área. A edição de 1998 do Relatório sobre o Desenvolvimento Humano (elaborado anualmente pelo Programa das Nações 
Unidas para o Desenvolvimento) pela primeira vez incluiu o Brasil entre os países de desenvolvimento social elevado. ${ }^{5}$ É evidente que não devemos nos iludir com esse êxito, pois as médias brasileiras encobrem discrepâncias significativas entre classes sociais ou entre regiões e raças. Não se coloca minimamente em dúvida a prioridade e a urgência do muito que há por fazer. Mesmo assim, os progressos registrados no chamado Índice de Desenvolvimento Humano (IDH) do Brasil não deixam de representar clara indicação de uma tendência positiva, que se reflete na melhoria de diferentes indicadores sociais: a expectativa média de vida passou de 52,7 anos em 1970 para 67,3 anos em 1995; a mortalidade infantil no primeiro ano após o nascimento caiu de 87,9/mil em 1970 para 43,4/mil em 1995; o percentual de analfabetismo na faixa de 7-14 anos diminuiu de 38,7\% em 1970 para 11,4\% em 1993.

Apesar do recente choque da desvalorização do Real, portanto, o Brasil continuará a ser percebido, por analistas e agentes econômicos que operam com a perspectiva do longo prazo, como um país que conta. Em seu mais recente livro (Years of Renewal), Henry Kissinger observa o seguinte: "Brazil has the resources, the population, and the scale to become one of the world's leading powers". Samuel Huntington considera que o Brasil seria uma das "grandes potências regionais", a exemplo do condomínio franco-alemão na Europa ou da Rússia na Eurásia. ${ }^{6}$ Em depoimento no Congresso norte-americano em janeiro passado, em período crítico da turbulência econômica que atingiu o Brasil, o Presidente do Federal Reserve Board, Alan Greenspan, disse que "o problema brasileiro é largamente fiscal. A economia do setor privado é uma entidade impressionante. Eles (os brasileiros) realmente construíram uma estrutura produtiva e um sistema financeiro muito sofisticados". ${ }^{7}$

Evidentemente, a diplomacia brasileira não se deixa levar por qualquer grau de ilusão quanto ao alcance desses comentários. A política externa brasileira não se baseia na busca de prestígio ou da afirmação externa do poder nacional, mas sim, tão somente, na preocupação em criar um ambiente externo que seja o mais favorável possível para o desenvolvimento nacional. ${ }^{8}$ Há plena consciência de nossas limitações internas e da complexidade dos desafios a superar. ${ }^{9}$ Mesmo assim, é útil manter presentes avaliações como as de Kissinger, Huntington ou Greenspan, pois servem para dar uma medida das possibilidades de atuação externa do país. É com essa perspectiva que trabalham os diplomatas brasileiros.

\section{O Brasil e a ordem internacional}

É efetivamente muito importante que o sentido de direção e a obstinação com que o governo brasileiro busca manter a inflação sob controle e, ao mesmo tempo, criar as condições para o desenvolvimento sustentável da economia sejam reconhecidos dentro e fora do país. 
Isso, porém, não é suficiente. Podemos melhorar o Brasil, tal como estamos empenhados em fazer. Mas é preciso que melhorem também as condições externas. Como todo país continental, é natural que o Brasil revele uma certa tendência à introspecção e à autarquia. Tendo sido dotado de uma eficiente rede de segurança externa no início do século, graças à visão estratégica da diplomacia do Barão do Rio Branco, o Brasil apresenta uma sociedade civil que - à exceção dos segmentos profissionais e do mundo dos negócios e das altas finanças - revela, no geral, reduzido grau de interesse relativo pelo fato externo. Pouco a pouco, não obstante, a sociedade vai-se mostrando mais permeável ao que acontece fora do país e verifica que os acontecimentos no plano internacional são determinantes para o quadro interno.

A relevância do fato externo para a definição dos rumos internos do Brasil não é, evidentemente, uma novidade. Os ciclos políticos e econômicos do BrasilColônia ou do Império sempre estiveram muito relacionados aos mercados internacionais (açúcar, ouro, café, borracha e assim por diante). Eventos-chave da história republicana foram também, em grande medida, decorrentes de acontecimentos externos. A Revolução de 1930, por exemplo, está ligada à crise econômica da lavoura do café, na esteira da depressão mundial de 1929. Mais recentemente, o esgotamento do regime autoritário e a transição para a democracia na primeira metade dos anos oitenta foram em boa medida decorrentes de uma situação de "estrangulamento" do balanço de pagamentos, que freou a economia e provocou forte queda da renda per capita no período 1981-83.

Mesmo assim, até recentemente, a percepção da importância do fato externo era de caráter mais esporádico e estava, no geral, ligada a acontecimentos específicos como as duas crises do petróleo (1973 e 1979) ou a crise da dívida externa (1982). Já agora, contudo, a opinião pública e os diversos segmentos organizados da sociedade passaram a acompanhar de forma mais consistente os acontecimentos internacionais. Firmou-se a consciência de que negociações como as do MERCOSUL, da ALCA ou da OMC, para citar exemplos mais presentes na mídia, têm impacto imediato para o desenvolvimento nacional. Nas últimas eleições presidenciais, ademais, o debate sobre formas de melhor controlar os efeitos da crise dos mercados financeiros internacionais esteve no centro da campanha eleitoral.

Daí nosso empenho renovado em contribuir positivamente para o debate que deve ocorrer com mais sentido de objetividade em torno de uma nova agenda de transformação da ordem internacional nos planos político, econômico e social. Mesmo tendo sido superados os riscos globais impostos pela confrontação LesteOeste, por trás da aparente simplicidade do modelo unipolar escondem-se elementos de ambigüidade, dispersão e disfuncionalidade que demandam uma reflexão cuidadosa. O poder internacional se exprime de maneiras freqüentemente surpreendentes e unilaterais; os mecanismos de organização internacional não 
acompanham de modo adequado as transformações em nível mundial, fato do qual é prova a incapacidade de reformar o Conselho de Segurança das Nações Unidas. Devido ao surgimento de diversos sistemas e subsistemas regionais, cuja ponderação internacional aumentou consideravelmente com a superação do maniqueísmo ideológico, verifica-se uma virtual tendência à fragmentação, com toda sua rede de rivalidades, de segmentações, de unilateralismos, de falta de visão de futuro e de busca de influências excludentes.

Essas realidades, que não são ainda compreendidas em todas as suas implicações, sugerem a necessidade de ver o quadro internacional sob novas perspectivas. Torna-se necessário operar com redobrado cuidado e especial criatividade. Sobretudo no caso de países como o Brasil, cujas complexas realidades nem sempre podem ser adequadamente expressas de maneira clara e para o qual há muito mais em jogo nos diferentes cenários internacionais - políticos, econômicos, comerciais, financeiros ou de segurança - do que a superação da Guerra Fria e da confrontação ideológica.

O fenômeno da globalização não afetou todos os países de forma equilibrada. São preocupantes tanto a autocomplacência que se apoderou dos países ocidentais depois do colapso do socialismo real quanto a falta de visão estratégica frente às situações de conflito e de exclusão que estão agravando-se na periferia do Primeiro Mundo.

O atual estado de coisas não poderia deixar de causar preocupação no Brasil. Com a autoridade que lhe confere o fato de estar implementando um programa bem estruturado de modernização e ajuste, o Brasil tem buscado enfatizar a necessidade de ampliar os debates sobre a ordem internacional. Temos tentado assinalar a importância de repensar adequadamente os acertos, os mecanismos e os procedimentos atualmente vigentes para adaptá-los aos desafios destes novos tempos da globalização.

Temos consciência de que o Brasil depende fundamentalmente do Brasil. Mas, ao mesmo tempo, sabemos que, por mais que a sociedade brasileira escolha de forma correta e racional todas as suas opções, tal como o faz, elas não serão por si próprias suficientes se os grandes países desenvolvidos não se mostrarem capazes de resolver seus conflitos de interesse e de atuar, em seu próprio benefício, como promotores coadjuvantes do crescimento e da estabilidade nas regiões periféricas.

Já não se trata, como em tempos anteriores, de uma agenda conflitiva ou reivindicatória. O mundo de hoje superou, felizmente, a retórica de confrontação. Mas não podemos deixar que se implante em seu lugar uma lógica de acomodação.

Se o mundo mudou com os avanços da tecnologia, com as proezas da comunicação, com a globalização dos mercados, é preciso mudar também as normas e as práticas ainda remanescentes do período anterior. Que momento melhor do que a virada do século para lançar um olhar analítico sobre as instituições e as 
formas de organização internacional que se originaram a partir da Segunda Guerra Mundial? Cresceram sob a rigidez das divisões ideológicas e agora parecem um tanto anacrônicas, pouco operativas e até certo ponto redundantes. Em recente entrevista, o Presidente Fernando Henrique Cardoso observou que "é preciso que as lideranças mundiais sentem-se novamente à mesa para estudar como conduzir o mundo no próximo século. É preciso definir novas bases. Se a ONU é um organismo excessivamente burocrático, é preciso definir qual o órgão ideal. Transferindo para o plano econômico e financeiro, é mais ou menos a mesma coisa". ${ }^{10}$

Afastado o perigo da confrontação global sob o qual vivemos durante décadas, deveriam estar dadas as condições para que a sociedade internacional se dedicasse novamente a pensar o futuro, a construir vínculos e instrumentos capazes de promover efetivamente a cooperação. O Brasil está preparado e desejoso de contribuir para essa meta, que deveria ser o grande projeto mobilizador, o maior empreendimento dessa virada de século.

O caminho a percorrer passa pelo reforço das instâncias multilaterais. Ou seja, repensar a ordem internacional em linhas que, ao acentuar e privilegiar a organização internacional, o façam em formas efetivamente associativas, não coercitivas.

Os dois vetores principais do processo de organização internacional, a segurança coletiva e a cooperação, são como as duas faces de uma mesma moeda. A segurança mais efetiva é, certamente, a que se baseia na cooperação. O mundo desenvolvido jamais poderá sentir-se seguro enquanto estiver cercado de miséria e atraso. As cidades brasileiras são, nesse sentido, uma metáfora da realidade internacional. Que cidadão do Rio de Janeiro ou de São Paulo pode sentir-se seguro de suas posses e de seus sentimentos, cercado por uma realidade urbana povoada de favelas, de criminalidade, de meninos de rua e tantas outras evidências de exclusão? Que cidadão norte-americano ou europeu pode não se sentir ameaçado pelas desigualdades da periferia do sistema internacional? No mundo da globalização dos mercados, é preciso não esquecer de que se globalizaram também os riscos. E de que se as áreas periféricas não forem rapidamente integradas aos benefícios do desenvolvimento, não serão os países do Terceiro Mundo os únicos prejudicados. A expansão dos países desenvolvidos baseada nos seus próprios mercados pode estar próxima de seus limites extremos, como o demonstram, sobretudo, os altos índices de desemprego que passaram praticamente a constituir fatores estruturais dessas economias.

Já nos anos cinqüenta, a diplomacia brasileira introduziu nas Nações Unidas um conceito talvez excessivamente adiantado para a época, o qual, hoje, poderia, não obstante, ser recuperado e devidamente atualizado para as circunstâncias de um mundo globalizado: a segurança econômica coletiva. Um conjunto de idéias e mecanismos que complementariam, no plano econômico, as instituições e os 
procedimentos destinados a garantir a segurança política e militar em nível internacional. Com a globalização, a demanda por mecanismos que garantam a estabilidade econômico-financeira e impeçam a eclosão de crises mundiais deixou de ser um desejo utópico para constituir-se em uma necessidade urgente que a comunidade internacional deveria debater com absoluta prioridade.

Há, é certo, sinais alentadores de movimento nessa direção, a exemplo da iniciativa dos países industrializados para alívio da dívida externa dos países de menor desenvolvimento relativo (HIPC - Highly Indebted Poor Countries) ou da recente criação de uma linha de contingência do FMI para apoio financeiro a países que tenham políticas macroeconômicas sólidas e que, mesmo assim, se vejam atingidos pela volatilidade dos mercados. Mas é necessário fazer muito mais. Trata-se de pôr a questão do desenvolvimento no centro da agenda internacional.

Há dados que falam por si. Segundo a edição de 1996 do Relatório do Desenvolvimento Humano, nos trinta anos anteriores, a participação na renda mundial dos $20 \%$ mais ricos passou de 70 para $85 \%$, enquanto os $20 \%$ mais pobres viram sua parcela decrescer de 2,3 para 1,4\% do total. No início dos anos noventa, o mesmo Relatório do Desenvolvimento Humano (edição de 1991) estimava que o protecionismo dos países desenvolvidos provocava uma perda anual de US\$ 100 bilhões nas exportações de produtos agrícolas dos países em desenvolvimento e de US\$ 50 bilhões nas exportações de produtos têxteis. Essa soma de US\$ 150 bilhões era cerca de duas vezes e meia superior ao montante global de ajuda oficial ao desenvolvimento - e, desde então, esse tipo de ajuda vem decrescendo paulatinamente, enquanto o protecionismo nos mercados dos países desenvolvidos segue no seu conjunto tendência oposta.

O Brasil tem procurado desenvolver uma linha de atuação externa sensível a essas condições e destinada a favorecer os consensos necessários para sua superação. A consolidação da democracia e a estabilidade macroeconômica conferiram ao Brasil, nestes últimos anos, a capacidade de recuperar uma margem razoável de iniciativa no plano internacional. Imersos no labirinto de nossa crise interna, havíamos perdido parte da capacidade de mobilização e iniciativa que, historicamente, caracterizou a política externa brasileira.

Estamos praticando uma diplomacia ativa, capaz de definir objetivos concretos e de granjear recursos em diferentes níveis para persegui-los. Tanto quanto possível, a democracia brasileira observa um padrão de conduta que se baseia em noções razoavelmente definidas de interesses em suas diferentes acepções. É nesse marco que se situa a prioridade estabelecida e operada pela diplomacia brasileira em duas áreas principais de atuação: o fortalecimento e a expansão das relações com os países da América do Sul e a busca de associações operacionais com os países desenvolvidos, em particular os Estados Unidos e a União Européia. É também nesse marco que se inscreve a prioridade atribuída ao 
conjunto de temas relacionados com integração, comércio, meio ambiente e direitos humanos. Nessas áreas geográficas e temáticas, o Brasil pratica políticas associativas que derivam de condições que o identificam como um país latino-americano em desenvolvimento. Mas desenvolve, sobretudo, uma série de ações decorrentes dos fatores que o singularizam no mundo como um país de grande massa territorial, um grande mercado, abundante em todos os principais fatores de produção e consumo, o mais desenvolvido parque produtivo da região, ou seja, os fatores que dão credibilidade e substância a sua reivindicação de maior participação no processo decisório internacional.

\section{A agenda de 1999 $^{11}$}

O desafio do desenvolvimento nacional é a prioridade do trabalho do Itamaraty. As questões da paz, da segurança ou da definição territorial do Estado - que são aquelas mais tradicionalmente associadas à imagem da diplomacia não representam preocupações imediatas para o país. Vivemos em paz com nossos vizinhos desde o final da Guerra do Paraguai, e temos com todos um padrão consolidado de relações fraternas e exemplares. É natural, portanto, a ênfase no desenvolvimento, reafirmada pelo Ministro Luiz Felipe Lampreia em discurso no último dia 30/4/99, por ocasião da formatura de nova turma de diplomatas. ${ }^{12}$

É evidente que as conseqüências de curto prazo da mudança do regime cambial e a perspectiva de queda do PIB brasileiro em 1999 dificultam em certa medida o exercício da atividade diplomática. A imagem que o Brasil havia reconstruído perante a comunidade internacional viu-se, por alguns momentos, novamente em jogo. A administração da agenda de negociações comerciais tornase mais complexa. As dificuldades enfrentadas no MERCOSUL neste início de 1999 pelo menos em parte são reflexo dessa nova situação.

O Itamaraty deve administrar no curto prazo, portanto, uma agenda com nossos principais parceiros que será marcada no plano econômico-comercial por menos convergências do que no passado recente. Essa situação não deve ser vista, contudo, como uma limitação à projeção externa de nossos interesses. Em primeiro lugar, porque as boas notícias de março/abril apontam para a manutenção da estabilidade econômica e a recuperação do crescimento a partir do segundo semestre. Em segundo, porque a diplomacia movimenta-se com a perspectiva do longo prazo, e mantém sua determinação de trabalhar para criar condições externas tão favoráreis quanto possível para a superação das situações de subdesenvolvimento com que o país ainda convive. Nessa linha de raciocínio, a agenda do Itamaraty para este ano de 1999 é particularmente densa, como se comenta a seguir. 


\section{(1) Crise financeira internacional}

Desde o início de seu primeiro mandato, o Presidente Fernando Henrique Cardoso vinha sugerindo à comunidade internacional a necessidade de maior cooperação internacional para o controle dos fluxos de capital. Esse tema foi objeto de palestra realizada na sede da CEPAL, em Santiago, em sua primeira visita ao exterior. Ainda em 1995, às vésperas da Cúpula de Halifax do G-7, o Presidente dirigiu cartas a todos os participantes, com a mesma mensagem. Desde então, o tema tem estado invariavelmente na agenda dos encontros internacionais do Presidente, do Ministro Lampreia e das autoridades da área econômica.

Está claro, portanto, que sempre estivemos atentos aos riscos da volatilidade dos capitais de curto prazo, mesmo nos momentos em que a situação do balanço de pagamentos não indicava a iminência de riscos. Não se trata, em outras palavras, de uma "prioridade de ocasião", motivada pelas dificuldades que levaram à mudança da política cambial do país e à perda em poucos meses de cerca de US\$ 40 bilhões em reservas.

Após a moratória russa em agosto de 1998, o debate ampliou-se, e o mundo passou a discutir com sentido de prioridade a necessidade de uma "nova arquitetura financeira internacional”. Trata-se, evidentemente, de uma discussão muito complexa, que envolve itens como a prevenção (transparência; early warning; regulamentação dos sistemas financeiros nacionais) ou o tratamento de crises (aumento dos recursos à disposição das instituições financeiras internacionais; linha de contingência do FMI; participação privada em esforços de resgate). Do ponto de vista diplomático, a preocupação essencial do Itamaraty diz respeito ao entendimento de que o Brasil deve necessariamente ter assento nos foros em que o tema da "nova arquitetura financeira internacional” seja discutido. ${ }^{13}$

Ressalte-se que as posições do Presidente Fernando Henrique Cardoso em favor de uma maior cooperação internacional para o controle dos capitais voláteis ou o entendimento brasileiro de que se deve incentivar a discussão de reformas no sistema financeiro internacional não refletem qualquer tipo de insatisfação quanto à forma com que a comunidade internacional reagiu às dificuldades de balanço de pagamentos do Brasil a partir do segundo semestre de 1998. O governo brasileiro tem bem presente o empenho dos governos dos países desenvolvidos (EUA à frente) e dos organismos financeiros internacionais para apoiar o país no momento necessário, como bem o demonstra a montagem do “pacote” de empréstimos no valor de US\$ 41,5 bilhões.

\section{(2) Protecionismo dos países desenvolvidos}

Se, em temas financeiros, o Brasil tem motivos para expressar reconhecimento pelo apoio externo que tem recebido, no campo comercial temos 
sérias razões de insatisfação. O Brasil vem sendo duramente penalizado pelas práticas protecionistas do mundo industrializado. Em recente estudo, o conhecido pesquisador norte-americano Gary Hufbauer estimou que o Brasil poderia exportar US\$ 6 bilhões a mais por ano para os Estados Unidos na ausência do arsenal de medidas protecionistas contra produtos como suco de laranja, açúcar e álcool, fumo ou siderúrgicos, entre outros. ${ }^{14}$

Na União Européia, as barreiras são ainda maiores. De acordo com estudo da economista Lia Valls Pereira, do IBRE/FGV, o PIB brasileiro teria um incremento anual de 2,08 e 5,05\%, respectivamente, na hipótese de conclusão de acordos de livre comércio com os EUA ou com a União Européia. ${ }^{15}$ Ainda que, à primeira vista, tal conclusão possa ser interpretada como recomendação de maior prioridade à aproximação com a UE, fica implícita a mensagem de que as barreiras comerciais européias impõem ao Brasil prejuízos superiores.

A diplomacia brasileira tem reforçado, nos últimos anos, sua atuação tradicional contra as barreiras protecionistas e as práticas desleais de comércio dos países desenvolvidos. ${ }^{16}$ Recentemente, tiveram grande repercussão as observações do Presidente Fernando Henrique Cardoso no Fórum-Empresarial MERCOSUL-Europa (Rio de Janeiro, 21 e 22 de fevereiro) sobre os efeitos negativos da Política Agrícola Comunitária para países como o Brasil. ${ }^{17}$ Essa mesma mensagem esteve no centro das conversações mantidas com os Chefes de Governo da Alemanha, de Portugal e do Reino Unido, por ocasião da primeira viagem do Presidente ao exterior em seu segundo mandato, em abril. ${ }^{18}$ Em maio, o tema esteve presente na agenda do encontro nos Estados Unidos com o Presidente Bill Clinton. Também neste primeiro semestre de 1999, o Ministro Luiz Felipe Lampreia tem estado à frente de negociações (ainda em curso) com os Estados Unidos a fim de procurar limitar os danos de medidas protecionistas contra produtos siderúrgicos brasileiros.

Esses exemplos são mencionados a título meramente ilustrativo. Como regra geral, pode-se dizer que o tema do protecionismo é invariavelmente parte da agenda dos encontros entre o Brasil e seus principais parceiros.

Em determinadas ocasiões, contudo, a opinião pública nacional tem demonstrado insatisfação com os resultados concretos das ações da diplomacia nacional contra o protecionismo dos países desenvolvidos. ${ }^{19}$ São recorrentes, apenas para citar um exemplo, as críticas aos resultados da negociação agrícola na Rodada Uruguai do GATT. É necessário considerar, contudo, que seria irrealista esperar que através da ação diplomática o Brasil e os outros países em desenvolvimento pudessem atingir plenamente todos os seus objetivos em termos de acesso aos mercados dos países desenvolvidos. O que está em jogo, nesse caso, é a dura realidade dos interesses concretos de poderosos lobbies nos Estados Unidos, na Europa ou no Japão, com grande capacidade de influência sobre os respectivos sistemas políticos internos. 
Assim, por exemplo, para voltar ao tema dos resultados da Rodada Uruguai no campo da agricultura, é evidente que não obtivemos o que desejávamos - ou o que seria objetivamente justo, na medida em que se possa usar essa palavra no campo das negociações econômicas internacionais. Mesmo assim, o simples fato de que a agricultura tenha sido pela primeira vez incluída nas disciplinas do comércio internacional já representou, por si só, um avanço. Ademais, logrou-se obter compromisso de retomada, justamente agora em 1999, de negociações para aprofundar os compromissos de liberalização do comércio internacional de produtos agrícolas.

Deve-se entender que as negociações internacionais são como um jogo de xadrez. Os ganhos são paulatinos, e não excluem a necessidade de sacrifícios táticos. Nesse jogo, não há espaço para voluntarismos ou pretensões maximalistas - especialmente no caso de países que, como o Brasil, não dispõem de "excedentes de poder”, para usar a expressão do ex-Chanceler Ramiro Saraiva Guerreiro. ${ }^{20}$

\section{(3) Integração regional: ALADI e MERCOSUL}

Os benefícios da integração regional para o Brasil constituem, em todos os tempos, uma das mais importantes contribuições da diplomacia nacional para o desenvolvimento do país. Em momentos em que havia, na melhor das hipóteses, cetismo ou desinteresse quanto a esses temas (por parte de outros órgãos do Governo ou do próprio empresariado nacional), o Itamaraty esteve à frente das negociações no âmbito da Associação Latino-Americana de Integração (ALADI, que, em 1980, substituiu a Associação Latino-Americana de Livre Comércio), do processo de integração bilateral iniciado com a Argentina em 1985 (quando os Presidentes José Sarney e Raúl Alfonsín assinaram a Ata de Iguaçu) e também das negociações do MERCOSUL (que estendeu em 1991 ao Paraguai e ao Uruguai o processo de integração entre Brasil e Argentina).

Hoje, o conjunto dos países da ALADI representa o principal mercado para as exportações nacionais de produtos manufaturados (42\% do total em 1997, sendo que apenas o MERCOSUL respondia por 28\%, percentuais bem acima dos dos Estados Unidos - 21\% - ou dos da União Européia - 16\%). Desde 1992, a Argentina é o segundo mais importante mercado para as exportações nacionais. Os países da região vão-se tornando importantes supridores de energia ao Brasil (petróleo da Argentina e da Venezuela; gás da Bolívia e da Argentina; eletricidade da Venezuela, e assim por diante), em um processo que cria uma teia de interesses recíprocos de caráter estratégico, e que representa garantia de aprofundamento da integração na América do Sul.

O Brasil tem em 1999 uma agenda particularmente densa no campo da integração regional. O MERCOSUL vem passando, neste primeiro semestre, pelo momento mais difícil desde sua criação, pela coincidência no tempo de uma série de fatores: 
- esgotou-se a etapa de ganhos fáceis com a integração, característicos da fase inicial de expansão de comércio em decorrência da desgravação tarifária automática. Após crescer ininterruptamente a taxas aceleradas entre 1991-97, o total do comércio intrazona apresentou ligeiro declínio em 1998, de cerca de 0,5\%, e deverá sofrer queda importante no ano em curso;

— no atual estágio da integração, a agenda de negociações passa a se concentrar em temas mais complexos, ligados à consolidação e ao aprofundamento da União Aduaneira (regime automotivo regional, medidas comuns de defesa comercial extrazona, defesa da concorrência, harmonização de regulamentos técnicos e sanitários, defesa do consumidor ou, ainda, a abertura dos mercados de serviços e de compras governamentais);

- pela primeira vez desde a assinatura do Tratado de Assunção, ambas as principais economias do bloco - Brasil e Argentina - passam por um período de retração, o que diminui os espaços de manobra dos negociadores e faz aumentar as pressões protecionistas dos setores que se sentem prejudicados pela integração;

— o chamado Regime de Adequação, que vigorou no período 1995-1998, e que havia permitido prolongar por tempo limitado, no comércio intrazona, a proteção tarifária a setores sensíveis, deslocou justamente para o início de 1999 o impacto da carga de sacrifícios da integração na Argentina. O Brasil, de sua parte, havia optado por incluir poucos produtos em suas listas de adequação, de modo que os impactos da liberalização comercial intrazona já haviam sido praticamente absorvidos por inteiro desde 1995.

Nesse período difícil, o Governo brasileiro e o Itamaraty continuarão a dedicar às negociações do MERCOSUL, por todas as razões, o máximo sentido de prioridade, com o propósito de manter as conquistas da integração sub-regional e de preparar as bases para novos avanços em momento oportuno. Foi com esse espírito que o Presidente Fernando Henrique Cardoso manteve em fevereiro encontros com os Presidentes de Argentina, Paraguai e Uruguai, e que os Chanceleres do Brasil e da Argentina se reuniram em Brasília em abril. A diplomacia nacional trabalhará com esse mesmo espírito na preparação das reuniões de cúpula a serem realizadas em junho (Paraguai) e em dezembro (Uruguai).

O Brasil espera concluir novos acordos de preferências tarifárias com Colômbia, Equador, Peru e Venezuela, e com isso lançar as bases para um futuro acordo de livre comércio entre o MERCOSUL e a Comunidade Andina. A realização desse objetivo é de grande prioridade para a diplomacia brasileira, não apenas por seus efeitos mutuamente benéficos para os países da região, mas, especialmente, por suas conseqüências em termos de fortalecimento da capacidade de atuação dos países da América do Sul em negociações internacionais de especial relevância para todos (ALCA, UE, OMC).

O Brasil está convencido de que, ao incentivar a conformação de uma grande área de prosperidade compartilhada na América do Sul, está contribuindo 
para criar, finalmente, as condições necessárias para que nossa região, como um todo, assuma um papel relevante no cenário mundial.

Também com o México espera o Brasil negociar novo acordo de preferências tarifárias. Os Presidentes Fernando Henrique Cardoso e Ernesto Zedillo mantiveram conversações a esse respeito por ocasião da visita ao Brasil do Chefe de Estado mexicano em abril.

\section{(4) A ALCA e o debate sobre a abertura comercial}

Em dezembro de 1994, representado pelo então Presidente Itamar Franco - que se fez acompanhar pelo Presidente-eleito Fernando Henrique Cardoso -, o Brasil participou da Cúpula das Américas em Miami, na qual se aprovou o compromisso de formação da ALCA até 2005.

Prevalecia naquele momento, no Brasil, uma visão favorável à aceleração de entendimentos sobre liberalização comercial (“choque” de concorrência para os produtores nacionais; modernização da economia; abastecimento da demanda adicional criada pelo Plano Real; controle da inflação). Em um ambiente de abundância de capitais nos mercados financeiros internacionais, não havia maior preocupação com a perspectiva de aumento das importações e de reversão dos elevados superávits comerciais que se registravam desde o início dos anos oitenta. ${ }^{21}$

Essa visão teve, naturalmente, de adaptar-se às transformações no cenário econômico mundial a partir de 1995. As sucessivas crises financeiras internacionais restringiram as condições de acesso a créditos externos. A ALCA tornou-se o epicentro dos debates no Brasil sobre o ritmo adequado para a abertura comercial. Em palestra na Escola Superior de Guerra, em 3/7/96, o Ministro Luiz Felipe Lampreia já advertia que "queremos evitar uma exposição precoce e descontrolada da economia brasileira a um segundo choque de abertura competitiva ao exterior e a economias muito mais produtivas do que a nossa, como a canadense e a norteamericana, antes de que se consolidem as adaptações e aperfeiçoamentos impostos pelo primeiro choque. Afinal, de 1990 para cá, fizemos uma ampla abertura comercial em três níveis - unilateral; regional, no âmbito do MERCOSUL; e internacional, no âmbito dos acordos da Organização Mundial do Comércio”. ${ }^{22}$

A reunião de Vice-Ministros da ALCA realizada no Recife em fevereiro de 1997 pode ser vista como o momento a partir do qual as autoridades brasileiras passaram a expor, de forma sistemática e com grande visibilidade para a opinião pública, essa nova visão sobre a integração hemisférica e a abertura comercial.

As novas condições não alteraram o compromisso brasileiro com a formação da ALCA. Os entendimentos em nível hemisférico podem ser instrumento valioso para superar obstáculos no acesso ao mercado norte-americano. Assim, o Brasil participou de forma ativa dos entendimentos que levaram ao lançamento 
das negociações para formação da ALCA, aprovado pela II Cúpula das Américas, em Santiago, em maio de 1998.

A diplomacia nacional tem atuado de maneira muito firme na defesa dos interesses do país nessa negociação. Em editorial do dia 12/8/98, O Estado de São Paulo registrou que "o Itamaraty vem operando com eficiência na discussão da Área de Livre Comércio das Américas ...”. O ritmo de criação da futura área hemisférica deve necessariamente ser compatível com a capacidade de adaptação da economia nacional (em especial dos setores industriais). O país não fará quaisquer concessões sem obter, em troca, compromissos concretos de desmantelamento das barreiras protecionistas norte-americanas. ${ }^{23}$

Em novembro, em Toronto, o Ministro Luiz Felipe Lampreia estará presente na próxima Reunião dos Ministros Responsáveis por Comércio das Américas. O Itamaraty continuará a participar desse processo com a mais plena consciência da responsabilidade que o tema lhe impõe, por suas profundas implicações políticas, econômicas e sociais para o país. Em seu discurso na III Reunião de Ministros Responsáveis por Comércio da ALCA, em Belo Horizonte, em maio de 1997, o Ministro Lampreia registrara que "estamos nos engajando no que será possivelmente a maior iniciativa de diplomacia comercial da maioria dos nossos países nos próximos anos”.

\section{(5) América Latina e Caribe-União Européia; MERCOSUL-UE}

Nos dias 28 e 29 de junho, teremos o privilégio de sediar a primeira cúpula entre Chefes de Estado e de Governo da América Latina-Caribe e da União Européia. Trata-se de uma ocasião de grande caráter simbólico, que reafirma os propósitos de aproximação entre as duas regiões.

A diplomacia brasileira tem trabalhado com muito empenho para que ocorra, à margem da cúpula, o lançamento de negociações entre o MERCOSUL e a UE com vistas à formação de uma área de livre comércio entre os dois agrupamentos, sem exclusão prévia de grupos de produtos. Essa questão esteve no centro das conversações que o Presidente Fernando Henrique Cardoso manteve com os Chefes de Governo de Alemanha, Portugal e Reino Unido, em sua viagem de abril último à Europa. ${ }^{24}$ No encerramento da redação deste texto, não é possível prever se teremos êxito nesse propósito. As preocupações de determinados países europeus em relação à liberalização do comércio de produtos agrícolas continua a representar um importante obstáculo. O MERCOSUL, de sua parte, não poderia aceitar o início de negociações com a exclusão dos produtos agropecuários, nos quais temos grande capacidade de competição.

O Brasil tem reiterado aos parceiros europeus, nos mais altos níveis, nosso interesse estratégico em manter um mínimo de paralelismo nas negociações sobre liberalização comercial na ALCA e com a UE. O Brasil não deseja vincular-se de 
forma preferencial a um único bloco comercial, por razões político-estratégicas e econômico-comerciais. Consideramos prioritária a manutenção do padrão histórico de equilíbrio relativo que se observa na repartição geográfica de nossos fluxos de comércio internacional e de IED. Esse padrão contribui para a manutenção da autonomia de nossa política externa e para que o Brasil disponha de maior espaço de manobra nas negociações econômicas internacionais.

\section{(6) Negociações comerciais multilaterais ("Rodada do Milênio”)}

Ao longo dos anos, o Itamaraty vem procurando desenvolver um trabalho de mobilização da sociedade nacional em torno da importância de que o país participe de forma muito ativa das negociações comerciais multilaterais no âmbito do GATT/ OMC. Trata-se de foro em que se toma decisões com profundas implicações para o desenvolvimento nacional. ${ }^{25}$

Em 1999, as negociações comerciais multilaterais continuam a exigir grande esforço de articulação externa e de mobilização interna por parte do Itamaraty. Até o final do ano, conforme compromisso que consta dos entendimentos finais da Rodada Uruguai, deverão ser retomadas as negociações para liberalização do comércio agrícola. No entendimento do Governo brasileiro, esse é o mais importante ponto da chamada built-in agenda da Rodada Uruguai.

O Itamaraty empregará toda sua capacidade de negociação externa na defesa dos interesses do agribusiness nacional. Para esse fim, estamos, desde já, trabalhando em estreita coordenação com os membros do Grupo de Cairns e com outros países igualmente empenhados na liberalização do comércio agrícola internacional. Evidentemente, as negociações serão, mais uma vez, muito duras, como já o foram na Rodada Uruguai, mas há fatores objetivos que permitem antecipar progressos na direção desejada. A UE vê-se diante de dificuldades orçamentárias crescentes - que se agravarão com a perspectiva de admissão de novos membros - para manter seus dispendiosos programas de apoio à produção e à exportação, que consomem cerca da metade do orçamento comunitário. Os EUA, de sua parte, parecem agora mais determinados do que na Rodada Uruguai em obter ganhos sensíveis na liberalização dos mercados agrícolas internacionais.

Em Seattle, em novembro próximo, será realizada nova Conferência Ministerial dos países membros da OMC, a terceira desde a entrada em funcionamento da organização em 1995. Tudo indica que deverá ser aprovado, na ocasião, o lançamento de uma nova rodada de negociações globais ("Rodada do Milênio"). Em seus contatos com os chamados major players, a diplomacia brasileira tem apoiado essa perspectiva, pois a dinâmica de uma "rodada" é mais favorável aos interesses dos países de menor peso relativo do que a dinâmica de negociações setoriais, nas quais os países mais fortes têm maior espaço de manobra para escolher os temas e ditar o ritmo dos entendimentos. Ao mesmo tempo, temos dito que o 
Brasil condicionará quaisquer compromissos de liberalização econômico-comercial a uma contrapartida de ganhos muito palpáveis em questões de nosso interesse, especialmente na área agrícola.

Diante da possibilidade de lançamento da “Rodada do Milênio”, encontrase o Itamaraty mais uma vez empenhado em promover a necessária coordenação interna para a definição dos interesses nacionais. O Governo Federal em seu conjunto, e o Ministério em particular, manterão o padrão de atuação, consagrado na ALCA, de estreita sintonia e entendimento entre os negociadores oficiais e a sociedade nacional. Esse padrão tem permitido ao Brasil falar com autoridade redobrada nos foros negociadores de que participamos.

\section{(7) Imagem}

A capacidade de um país de influir em negociações internacionais, vender seus produtos, atrair investimentos, receber créditos, participar de programas conjuntos nas áreas da ciência e da tecnologia, obter ganhos com o turismo, enfim, a capacidade de promover seus interesses internacionais depende não apenas de fatores objetivos, mas também da sua imagem externa. Por isso, quando o Itamaraty se empenha, continuamente, em mostrar e explicar a realidade brasileira aos nossos interlocutores e à opinião pública internacional o que está em jogo são desdobramentos que irão ter reflexos concretos no bem-estar da população. O assunto não é de interesse apenas para o Governo do momento, mas sim para o país e para a sociedade.

Em recente entrevista, o Ministro Luiz Felipe Lampreia definiu os espaços para a atuação do Itamaraty nessa matéria: “A imagem é sempre em função de uma realidade. No regime militar se falava muito em melhorar a imagem, mas ninguém tapa o sol com a peneira, ninguém vende uma coisa que não existe. Você só melhora uma imagem se você melhorar uma realidade” (Correio Braziliense, "Exportar é a melhor aposta”, 14/3/99).

O Itamaraty deve trabalhar, portanto, com a meta de que a imagem do país deva corresponder à realidade nacional. Nossa tarefa consiste em informar, esclarecer, apresentar dados. Infelizmente, por toda uma série de fatores, o que ainda se observa é que a imagem do Brasil é pior do que sua realidade. Não se trata de procurar negar a gravidade de nossos problemas econômicos e sociais, mas parece claro para o profissional da diplomacia - acostumado ao contato diário com a mídia e com ONGs internacionais - que o Brasil real é melhor do que sua imagem no exterior.

Procurar entender os motivos dessa situação iria além dos limites deste texto. Fica a impressão, contudo, de que nossos problemas de imagem têm muito a ver com a psicologia nacional, que tende a ecoar com muita força os julgamentos negativos sobre o próprio país, ao mesmo tempo em que coloca em segundo plano 
nossas realizações. ${ }^{26}$ Em boa medida, essa é uma atitude salutar, pois mantém o Governo e a sociedade permanentemente mobilizados em torno da necessidade de encaminhar soluções para os dramas sociais do país e para tantos outros aspectos negativos de nossa realidade. Ao mesmo tempo, como argumentado acima, essa postura pode ser também prejudicial, e, por isso, o Itamaraty trabalha para que haja maior sintonia entre imagem e realidade.

As viagens presidenciais, além de sua importância intrínseca, constituem parte essencial dos esforços do Itamaraty no campo da imagem. Nessas ocasiões, o Presidente Fernando Henrique Cardoso invariavelmente mantém contatos com a comunidade empresarial, os meios acadêmicos, as ONGs e outros grupos relevantes dos países visitados. Em 1999, o Presidente já esteve na Alemanha, em Portugal, no Reino Unido e nos Estados Unidos, dando continuidade à sua intensa agenda de envolvimento pessoal na promoção dos interesses do Brasil no exterior. ${ }^{27}$

Como se vê, essa simples enumeração seletiva e necessariamente muito incompleta permite ao leitor uma visão bastante ampla da densidade da agenda diplomática brasileira em 1999 e de sua relevância para o processo de desenvolvimento nacional. O Itamaraty deve ainda ocupar-se de toda uma série de vários temas não menos importantes, a exemplo, entre outros, da participação do país - como membro não-permanente eleito para o biênio 98/99 - no Conselho de Segurança da ONU, no qual estão em pauta temas como Iraque, Angola ou Timor Leste; da definição de nossas posições em situações de crise como a do Kosovo; da condução de nossas relações com os vizinhos sul-americanos e demais parceiros mais importantes do país; da atuação nos vários foros internacionais que tratam dos temas do meio ambiente, direitos humanos, não-proliferação ou narcotráfico; da promoção comercial no exterior, em apoio aos exportadores brasileiros; da assistência consular a brasileiros no exterior, e assim por diante.

O Brasil está mais do que nunca interessado em acentuar seus vínculos com os países com os quais compartilha afinidades, interesses e, em especial, grandes projetos estratégicos, como é o caso especial do MERCOSUL. Para utilizar as expressões do Barão do Rio Branco, "por aspiração de sua cultura, pelo prestígio de sua grandeza territorial e pela força de sua gente, o Brasil considera poder contribuir positivamente para o encaminhamento das grandes questões internacionais”. Ao cumprir com essa tarefa, o Itamaraty estará dando sua contribuição para o desenvolvimento nacional. 


\section{Notas}

1 Ver Carlos Eduardo LINS DA SILVA, “Brasil cresce no plano externo”, Folha de São Paulo, 3/ 2/99. Essa matéria reflete, com grande capacidade de síntese, a riqueza e a diversidade da agenda externa brasileira, e o aumento da projeção externa do país. Ver, também, TIME, “The odd man out is back in”, 20/10/97, p. 36; Financial Times, “Brazil’s coming of age”, 28/10/97, p. 19.

“ (...) quando Euclides da Cunha, na passagem para o século XX, ou, mais recentemente, Oliveira Viana, no Brasil dos anos 40, falavam do sertão, da marginalidade, do atraso, era para afirmar suas próprias versões da civilização, do progresso, da modernidade. Em outras palavras: eles afirmavam o futuro" (Francisco WEFFORT; A América Errada, Qual democracia? São Paulo: Companhia das Letras, 1992).

O Estado de São Paulo, 26/8/98.

Gazeta Mercantil, "Investimento direto financia déficit”, 24 a 26/4/99.

VEJA, “O mais difícil foi feito”, 16/9/98. Em 1995, o Índice de Desenvolvimento Humano do Brasil, que combina indicadores de educação, renda e expectativa de vida, foi de 0,809 em uma escala de 0 a 1. Em 1960, o IDH brasileiro era de 0,394 - equivalente ao que apresentam hoje Zâmbia e Bangladesh.

Samuel P. Huntington, “A superpotência solitária”, Foreign Affairs (edição brasileira - caderno da Gazeta Mercantil, n. ${ }^{\circ}$ 30, março de 1999).

O Estado de São Paulo, “Problema brasileiro é fiscal, diz Greenspan”, 21/1/99.

“... não devemos, nem podemos, alimentar visões de projeção global de nosso poderio políticomilitar. As carências que enfrenta o povo brasileiro não permitem, de modo algum, a mobilização dos enormes recursos necessários para dar lastro e credibilidade a um projeto dessa natureza, como em algum momento imaginaram os defensores da idéia do 'Brasil-potência'” (Luiz Felipe LAMPREIA, Discurso na transmissão do cargo de Secretário-Geral das Relações Exteriores, 4/ 1/99).

"(Brazil is) one of the world's most diverse societies in its fifth most-populous country. Its $160 \mathrm{~m}$ citizens range from Amerindian forest-dwellers to academics and businessmen as sophisticated as any in the world. It has areas much like parts of southern Europe, others barely distinguishable from (peaceable) parts of West Africa” (The Economist, "Brazil's steady nerve”, 10/10/98, p. 15).

O Estado de São Paulo, "FHC diz que EUA devem partilhar decisões”, 22/4/99, p. A4.

A definição das prioridades da diplomacia brasileira em 1999 foi objeto de discurso pronunciado pelo Ministro Luiz Felipe Lampreia no dia 4/1/99, acima referido. Ver, também, Luiz Felipe LAMPREIA, “Política externa em 1999”, O Estado de São Paulo, 26/2/99.

“A solução sistemática das questões fronteiriças empreendida no decênio da gestão do Barão do Rio Branco (1902-12) e nos anos subseqüentes (...) cria as condições de possibilidade para dirigir crescentemente a política exterior para objetivos de cooperação e desenvolvimento. Consolidado o território, era preciso desenvolvê-lo” (Rubens RICUPERO, “A diplomacia do desenvolvimento”. Três Ensaios sobre Diplomacia Brasileira. Brasília: MRE, 1989).

Ver Folha de São Paulo, "FHC propõe a Tony Blair a ampliação do G-7”, 20/4/99.

Folha de São Paulo, "Para americano, EUA fazem Brasil perder US\$ 6 bilhões”, 5/4/99. Para a Confederação Nacional da Agricultura, haveria uma perda anual de US\$ 5 bilhões provocada pelas barreiras dos EUA apenas contra produtos agrícolas (O Estado de São Paulo, "Barreiras impedem vendas de US\$ 5 bi para os EUA”, 2/9/98).

Gazeta Mercantil, "País lucra mais com UE do que com ALCA”, 2/5/97; O Estado de São Paulo, “Técnicos consideram Europa mais vantajosa”, 13/5/97.

Ver O Estado de São Paulo, “O protecionismo europeu e o Mercosul”, 23/2/99. Esse excelente editorial proporciona uma visão bastante ampla da atuação do Brasil em diversas frentes contra o protecionismo dos países industrializados. Ver, também, The Economist, "Latin America and 
Europe. Slowly, slowly”, 6/12/97, p. 58: "Not often, in public at least, are state visits marked by plain speaking. But the European Union, its governments and its farmers got an earful — if they were listening — from Brazil's President Fernando Henrique Cardoso in London this week. ... he had words of acid for the EU's farm policy ...”.

"O Presidente Fernando Henrique Cardoso foi tão duro quanto poderia ser o país anfitrião, ao abrir o Fórum Empresarial Mercosul-União Européia: condenou em termos veementes o protecionismo dado pelos países europeus à agricultura ...” (O Estado de São Paulo, “O protecionismo europeu e o Mercosul”, 23/2/99).

Ver Alberto TAMER, "Brasil não deve se iludir com mais promessas de abertura comercial”. O Estado de São Paulo, 18/4/99.

Ver, por exemplo: (1) O Globo, "Hora de cobrar”, 11/8/98; (2) Alberto TAMER, "Brasil protesta, Europa ouve e até concorda, mas não muda nada”, O Estado de São Paulo, 28/2/99, p. B9; (3) Gazeta Mercantil, “Maior pressão contra o protecionismo”, 8/3/99.

Ver Luiz Felipe LAMPREIA, “Diplomacia, jogo duro”, Folha de São Paulo, 7/3/99; “Bananas e aviões”, Gazeta Mercantil, 15/3/99.

Ver, a título de exemplo, entrevista do ex-Presidente do Banco Central, Gustavo Franco: Folha de São Paulo, “Déficit não é ‘esquisito’, afirma Franco”, 9/3/97, p. 1-20).

Ver, também, declarações do Presidente Fernando Henrique Cardoso durante visita ao Reino Unido em fevereiro de 1997: Jornal do Brasil, "FH põe freio na abertura da economia”, 10/2/ 97; Folha de São Paulo, “FH diz que Brasil 'precipitou’ abertura”, 10/2/97.

Ver The Economist, "Rediscovering the Americas", 17/5/97, p. 16 ("Along the long route to free trade, the Brazilians have vigorously challenged the American road map. You have interests, they say, so do we; you have to listen, just as we do") ; “A new world”, 25/4/98, p. 37 (“Since the FTAA idea was born in 1994, the leading force — not always in that direction, and often challenging the Americans - has been Brazil. ... it has vigorously pressed its view of how the FTAA haggling should proceed — and won much of its point”).

A imprensa nacional noticiou com grande destaque essa ofensiva diplomática. Ver, por exemplo: Folha de São Paulo, "Brasil cobra União Européia”, 15/4/99; Gazeta Mercantil, “Alemanha promete ajuda contra barreiras”, 16/4/99; O Estado de São Paulo, "FHC dá ultimato para União Européia negociar”, 17/4/99, p. A8; O Estado de São Paulo, "FHC ganha apoio de Blair para zona de comércio”, 20/4/99, p. A4; Folha de São Paulo, “Blair apóia união de blocos”, 20/ 4/99 (“O governo brasileiro fechou ontem o círculo de apoio à concessão do chamado mandato negociador para que a União Européia inicie efetivamente as negociações com o Mercosul para a formação, a partir de 2005, de uma zona de livre comércio entre os blocos. Obteve a concordância do primeiro-ministro britânico Tony Blair ... Antes, os primeiros-ministros Gerhard Schroeder (Alemanha) e António Guterres (Portugal) haviam manifestado apoio”).

Em artigo de imprensa, o Ministro José Serra registrou, em relação à Rodada Uruguai, "os esforços do Itamaraty, que fez o possível para despertar, sem sucesso, nos sucessivos governos brasileiros, a consciência da enorme importância do assunto” (José SERRA, “Começo do começo”. Folha de São Paulo, 19/5/97). Ver EXAME, “Estamos tão mal assim?”, 8/5/96 (a.29, n. 10).

27 Sobre a importância em geral das viagens presidenciais, ver Sebastião do REGO BARROS, “A execução da política externa brasileira: um balanço dos últimos 4 anos”. Revista Brasileira de Política Internacional (a.41, n. $\left.{ }^{\circ} 2,1998\right)$. A respeito do tema da imagem, caberia um registro final a respeito da forma correta com que órgãos da imprensa internacional como a The Economist, o Financial Times ou o Frankfurter Allgemeine Zeitung descrevem os fatos brasileiros. Essas publicações são exemplo de jornalismo sério, no qual as críticas aos tantos aspectos negativos da realidade brasileira é feita de forma equilibrada, sem excluir referências ao que há de positivo no país e ao que se procura fazer para melhorá-lo. Ver, por exemplo, The Economist, “A Survey of Brazil. The disorders of progress”, 27/3/99. 
Resumo

Durante o primeiro mandato do Presidente Fernando Henrique Cardoso, a renovação do sentimento de autoconfiança do país e o respeito da comunidade internacional favoreceram a política externa. Diante das dificuldades econômicas na virada de ano 1998-99, a diplomacia deve manter a visão do longo prazo. O Brasil continua a ser um "país que conta”, e que depende fundamentalmente de si próprio para desenvolver-se. Mas é também preciso que melhorem as condições externas. O Brasil empenha-se em contribuir para os debates sobre transformações na ordem internacional. A tarefa prioritária da diplomacia nacional é a de criação de condições externas tão favoráveis quanto possível para o desenvolvimento. A agenda externa do país em 1999 - crise financeira internacional; protecionismo dos países industrializados; integração regional (MERCOSUL, Comunidade Andina, México); ALCA; Cúpula América Latina e Caribe-Europa; negociações agrícolas e "Rodada do Milênio" na OMC; imagem - tem conseqüências importantes para o processo de desenvolvimento nacional.

\section{Abstract}

The renewal of the country's self-confidence and the earned respect from the international community were two important assets for the Brazilian diplomacy during President Fernando Henrique Cardoso's first term. Faced with the country's economic difficulties in the end of 1998 and beginning of 1999, diplomacy must keep in mind a long term view. Brazil will continue to be a "country that counts", which fundamentally depends on itself to develop. But the improvement of external conditions is also necessary. Brazil is willing to give its contribution to the discussions about changes in the international order. Brazilian foreign policy's priority is the creation of the utmost favourable external conditions for development. The foreign agenda of the country in 1999 - international financial crisis; industrialized countries' protectionism; regional integration (MERCOSUR, Andean Community, Mexico); FTAA; Latin America and the Caribbean-Europe Summit; agricultural negotiations and the WTO “Millennium Round"; image - has important consequences for national development.

Palavras-chave: Brasil. Diplomacia. Política exterior. Key-words: Brazil. Diplomacy. Foreign policy. 